\title{
Cerro Respiro y la administración inca en el valle bajo del Chillón
}

\section{Cerro Respiro and the inca administration in the Chillon lower valley}

\author{
Gil Ronal Ayala Castillo \\ https://orcid.org/0000-0003-3201-7088 \\ Universidad Nacional Federico Villarreal \\ gilronalayala@hotmail.com
}

\section{RESUMEN}

El presente artículo es resultado de las investigaciones realizadas en el sitio Cerro Respiro ubicado en la margen derecha del valle bajo del Chillón, muy próximo a la desembocadura el río Chillón. Los trabajos llevados en el sitio tuvo como corolario dar una explicación sobre su cronología y funcionalidad del sitio relacionado de manera directa con la organización político-administrativo a partir de los edificios definidos como residencias de élite y los espacios públicos, cuyas características arquitectónicas la definen como tal, donde los contextos excavados y las evidencias culturales fueron definidas al periodo Intermedio Tardío y Horizonte Tardío, las cuales sirven de sustento al problema planteado.

El sitio es explicado en base a un análisis arquitectónico comparativo de tres asentamientos que comparten construcciones residenciales de élite y habrían desempeñado esta misma función en el valle del Chillón. Este tipo de instalaciones incas habrían sido el resultado del proceso de conquista de manera directa, estrategia llevada a cabo por el estado inca, con el afán de controlar recursos humanos, agrícolas y naturales desde los palacios o residencias de élite ubicados en puntos estra- 
tégicos del valle bajo del Chillón, articulados a una red de caminos de las cuales aún quedan evidencias.

Palabras clave: Horizonte Tardío, Chillón, residencia de élite, camino inca, control administrativo.

\section{ABSTRAC}

This article is the result of investigations carried out at the Cerro Respiro site located on the right bank of the lower Chillón valley, very close to where the Chillón river flows. The works carried out on the site had as a corollary to give an explanation about its chronology and functionality of the site, directly related to the political-administrative organization from the buildings defined as elite residences and public spaces, whose architectural characteristics define it as such, where the excavated contexts and cultural evidences were defined to the Late Intermediate and Late Horizon period, which serve as support to the problem posed.

The site is explained based on a comparative architectural analysis of three settlements that share elite residential buildings and would have performed the same function in the Chillón valley. This type of Inca facilities would have been the result of the conquest process directly, a strategy carried out by the Inca state, with the aim of controlling human, agricultural and natural resources from the elite palaces or residences located in strategic points of the valley under del Chillón, articulated to a network of roads of which there is still evidence.

Keywords: Late Horizon, Chillón, elite residence, inca trail, administrative control.

ReCibidO: 04/09/2021 - ACEPTADO: 26/09/2021 - PublicAdo: 25/11/2021

\section{ANTECEDENTES}

El Chillón tiene una configuración geográfica y ecológica muy compleja, debido a su topografía donde podemos diferenciar tres espacios ecológicos bien marcados como son: valle bajo, valle medio y el valle alto. Nuestro interés está focalizado en la cuenca baja, zona ecológica donde encontramos una ocupación humana prehispánica desde los pedidos tempranos hasta el Horizonte Tardio y que nos ha permitido conocer de manera particular el espacio social construido y transformado como consecuencia del impacto inca, el mismo que es observable en las evidencias materiales recuperadas en intervenciones arqueológicas del sitio Cerro Respiro, así como en la arquitectura residencia de élite en los sitios de Palacio Oquendo y Tambo Inca, en cuanto a su diseño, formas, materiales, elementos arquitectónicos incorporados por los incas en estos asentamientos que tienen una ocupación del periodo anterior. 
La incorporación de infraestructura y equipamientos arquitectónicos inca es identificable en la consecuente modificación de la composición urbana al interior de cada sitio mediante la construcción de los edificios residenciales de élite, plazas, depósitos y kallancas, así como instalaciones ubicadas en los extramuros asociados al camino inca, los cuales expresan una relación directa con la política coercitiva y de apropiación de territorios, el repoblamiento de población foránea, implantación de políticas de tributos y la prestación de servicios a favor del estado inca.

\section{LA CONQUISTA INCA}

Antes de la conquista inca, el señorío de Colli dominaba el valle bajo y medio del Chillón desde la cercanía del mar hasta la zona de Quívis. La organización política de este señorío estuvo conformada por una unidad independiente muy bien consolidada que integraba a jefes locales de menor rango al interior del valle bajo y medio, con definición de territorios y linderos establecidos para cada grupo de población (Rostworowski, 1972, p. 26-28).

Los datos etnohistóricos manejados por Dillehay (1976), Rostworowski (1982) señalan que la integración del valle del Chillón al Tawantinsuyo fue mediante la conquista de la guerra, llevada a cabo por Inca Túpac Yupanqui aproximadamente en la segunda mitad del siglo XIV. Se mencionan también que el Señorío Collique ofreció resistencia a los Incas, dando lugar a enfrentamientos en la que perdieron los ejércitos yungas, donde el señor principal fue muerto en combate y luego asumió como principal el curaca de Quivi (Rostworowski, 1972, p. 33).

Los documentos etnohistóricos hacen referencia a un hecho importante en este proceso de conquista, la estrategia habría sido el exterminio de la población local orientado a lograr la consolidación y el control político por parte del Estado Inca en el valle, al respecto (Rostworowski, 1972, p. 34-45) relata:

[que el curaca de Quivi Chaume Caxa fue acusado de conspirar contra la salud del Inca Tupac Yupamqi, como resultado el curaca fue conducido preso al Cusco, donde fue ejecutado por traición producto de este hecho la represión en Quivis fue sangrienta, todos los hombres fueron muertos, sólo mujeres y niños quedaron vivos].

$\mathrm{Al}$ analizar estos hechos se observa que la dominación Inca en el valle del Chillón trastocó el antiguo orden social, político y territorial de las poblaciones locales del periodo anterior caracterizado por constantes rivalidades entre los grupos de la sierra y la costa por el control de los recursos del valle medio. Como parte de este proceso se describen hechos que reflejan cambios profundos en un nuevo orden político y administrativo como es el "exterminio" de la población local, el repoblamiento de nuevas poblaciones como los Cantas y Chacllas que van a ser asentados en el valle medio y bajo y la imposición de nuevas autoridades en el territorio conquistado. 
Se menciona, que las tierras de los cocales de Quívis ubicadas en el valle medio del Chillón fueron entregadas después de la conquista inca al grupo de los Chacllas y Cantas colaboradores de los incas y estos cumplieron trabajos de mitmaq en la producción de bienes de alto valor económico como la coca, el algodón y otros para el estado inca (Rostworowski, 2014. p. 68). Es decir, el proceso de dominación transformó la organización del territorio a nivel constructivo, por lo que se desconoce si estas poblaciones impuestas por el estado inca construyeron edificios públicos para satisfacer las necesidades estatales en el nuevo territorio conquistado.

En tal sentido, la consolidación y dominación Inca en el valle bajo del Chillón, fue compleja y directa que involucró la remoción de las élites locales gobernantes de sus puestos de autoridad política y religiosa, siendo remplazados por una administración inca foránea. Se afirma que tras la muerte del señor de Collique ningún curaca local asumió el mando, sino el Inca puso como señor a un yanacon yanayacu (Rostworowski, 1972, p. 34-35). Estos hechos, evidenciarían que la conquista inca trastocó el antiguo orden sociopolítico en el valle medio y bajo del Chillón, estableciéndose por tanto un nuevo orden político y administrativo.

Consolidada la conquista de este territorio, el valle del Chillón pasó a formar parte política y administrativamente de la provincia inca de Pachacamac, que estuvo conformado por los valles de Lurín, Rímac y Chillón (Cornejo, 2000).

En este nuevo orden político, la provincia Inca de Pachacamac comprendió tres hunos, éstos fueron: Pachacamac y el bajo Lurín que formaron un huno con el señorío de Surco en el Rímac. El segundo huno fue el Rímac con su capital en Maranga y el tercero abarcó el extremo norte del valle bajo del río Rímac y el valle bajo del río Chillón con su capital Carabayllo (Cobo, 1882[1639]: 391).

Según Cornejo (2000), en el valle del Chillón durante la ocupación inca había tres guarangas, cada una consistía en 1000 familias, estas eran: La guaranga de los Colliques ubicado en el valle bajo. La guaranga de los Yangas en el valle medio y la guaranga de los Cantas ubicados en el valle alto.

Investigaciones arqueológicas en el valle medio y bajo han reportado sitios con ocupación Inca como los sitios de Huancayo Alto, Macas, Cerro Macas, Trapiche Huarabí Alto, Huarabí Bajo, Huanchipuquio A, Huanchipuquio B, Zapan A y B, Collique, Tambo Inca, Cerro Respiro y Palacio Oquendo de los cuales muy poco se conoce. La distribución de sitios con ocupación inca parece responder a un tipo de organización política y administrativa implantado por el estado en un territorio conquistado con el afán de controlar el valle mediante estrategias como el repoblamiento de población en calidad de mitmas en el valle del Chillón, la implantación de nuevas autoridades foráneas, el control de las tierras y de los principales recursos del valle. 
Según Aranguren (2005) sobre este planteamiento menciona:

"que los indios comuneros de Huancayo Alto poseían tierras durante la colonia en la hacienda San Lorenzo, asi como indios de Canta, indios del antiguo pueblo de Macas y de la parcialidad de Miray (Misais) poseían tierras en la hacienda la Molina antes de ser trasladados al pueblo de Carabayllo" (Aranguren, 2005).

Los datos expuestos evidencian que poblaciones como los Cantas y Macas del valle medio y alto del Chillón, en el Horizonte Tardío habrían conseguido tierras en el valle bajo, como parte de una nueva organización política inca.

Si consideramos la guerra como una forma de dominación, debemos preguntamos si estas estrategias influyeron en la forma de la administración del valle, la construcción y distribución de los asentamientos incas. Si fue así, entonces cuáles fueron las características de estos asentamientos. Según las investigaciones llevadas a cabo en el 2016 en el valle bajo se observa que los incas ocuparon sitios del periodo Intermedio Tardío, en estos edificios se construyeron ambientes adaptados a nuevas funciones específicas reproduciendo el modelo arquitectónico de los grandes centros administrativos, en este caso, de tamaño pequeño, el cual ha sido definido arquitectónicamente como residencias de élite o palacios, viviendas de señores locales, los mismos que expresan una racionalidad distinta en cuanto a criterios de edificación, ornamentación y función, como es el caso del sitio Cerro Respiro, Tambo Inca y Palacio Oquendo.

Si bien los documentos etnohistóricos brindan información para el valle medio, no se tiene referencias sustanciales sobre las transformaciones territoriales en el valle bajo del Chillón. En la visita de Juan Martínez Rengifo realizada al valle del Chillón en 1571, los nombres de las antiguas Pachacas de los Collis en tiempos de los Incas fueron mencionadas, estas son: [Chuquiruro, Caxa Chumbi, Vilca Tanta, Vilca Chumbi, Chumbi Guarco, Chumbi Tanta, Carua Guanco, Carua Chumbi, Chinqui Yanga y Chuquitanta, nombres quechuas que al parecer corresponden a apellidos de señores Yunga] (Rostworowski, 1972. p. 45).

Si se toma como referencia válida esta información, se puede indicar que, en tiempos de los incas, el valle bajo estuvo dividido en diez pachacas cada una conformada por100 familias, lo que concuerda con el sistema implantado por los Incas. El nombre de Chuquitanta hace referencia en la actualidad a la ex-hacienda de Chuquitanta, localizada en la parte baja del valle del Chillón.

En esta zona del valle bajo, se han identificado evidencias arqueológicas de asentamientos con cultura material inca e instalaciones domésticas (Cerro Santa Cruz), cementerios (Pampa de las Animas) y evidencias de una red vial en la zona de Chuquitanta hasta Puente Inca y el sitio Cerro Respiro, este último el más importante 
ubicado en la margen derecha relacionado al parecer a la pachaca de Chuquitanta en tiempos del dominio Inca.

En este contexto político la pachaca de Chuquitanta habría conformado una unidad política, relacionada al puesto de autoridad de un señor (autoridad local) con facultades políticas y administrativas y debió localizarse en el sitio de Cerro Respiro.

\section{CERRO RESPIRO}

Registrado también como Puente Inca, se ubica en la margen derecha del río Chillón, en la falda del cerro denominado Cerro Respiro, junto al Asentamiento Humano moderno Nueva Esperanza, cerca al lugar llamado Puente Inca, límite entre los distritos de Ventanilla y Puente Piedra. Geográficamente se sitúa en el distrito de Ventanilla, región Callao, departamento de Lima (figura 1).

El asentamiento se emplaza un área de pequeña quebrada, cuya superficie está conformada por arena eólica y áreas rocosas ubicadas hacia la falda del cerro, contiene en su interior un conjunto de estructuras de tapial distribuidas en un espacio de 4.2 hectáreas aproximadamente. En esta área los incas han construido recintos

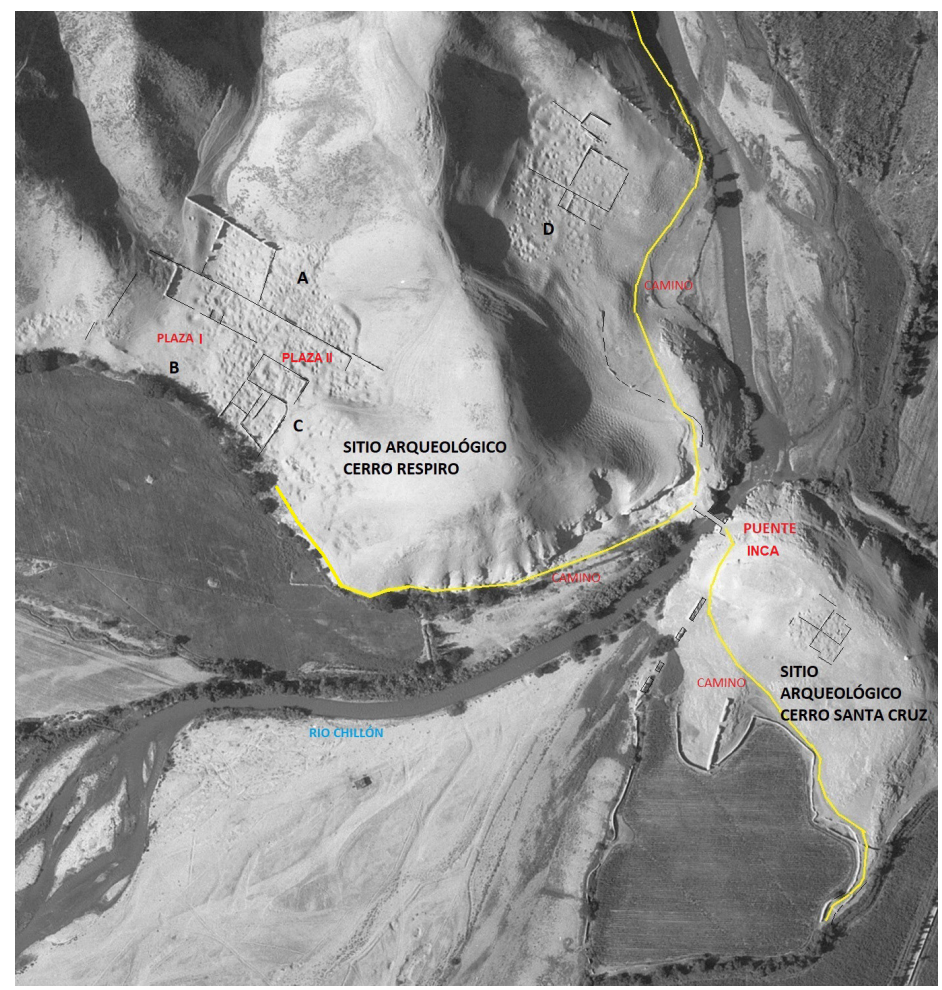

Figura 1. Cerro Respiro, se muestra los cuatro sectores asociados al puente, el camino inca y el sitio arqueológico Cerro Santa Cruz (fuente ESAN. Vuelo 112-144. Año 1945). 
de planta ortogonal que definen estructuras diferenciadas en cuanto a su diseño arquitectónico y función, como un edificio residencial, espacios públicos (plazas), depósitos y áreas funerarias (figura 2).

Una estructura de baja altura y de base ancha se extiende de noreste a sureste de la quebrada y en el extremo este presenta un acceso restringido en forma de "L" relacionado con la plaza II y el camino que comunica al sitio con la zona de Márquez y el mar de Ventanilla. Un segundo acceso al sitio se localiza en el extremo sur del sitio, junto a la plaza I que comunica la zona de Puente Inca.

Es parte del sitio, la cima intermedia que se prolonga desde la zona de Puente Inca hacia la ladera medía del Cerro Respiro, comprende una pequeña saliente y espacio elevado de dominio panorámico de toda el área del valle. En la parte baja de la carretera cerca al sitio, se encuentra el puquial o fuente de agua del asentamiento, el mismo que en la actualidad sigue siendo aprovechado como parte del sistema de riego de la acequia Monte Culebra.

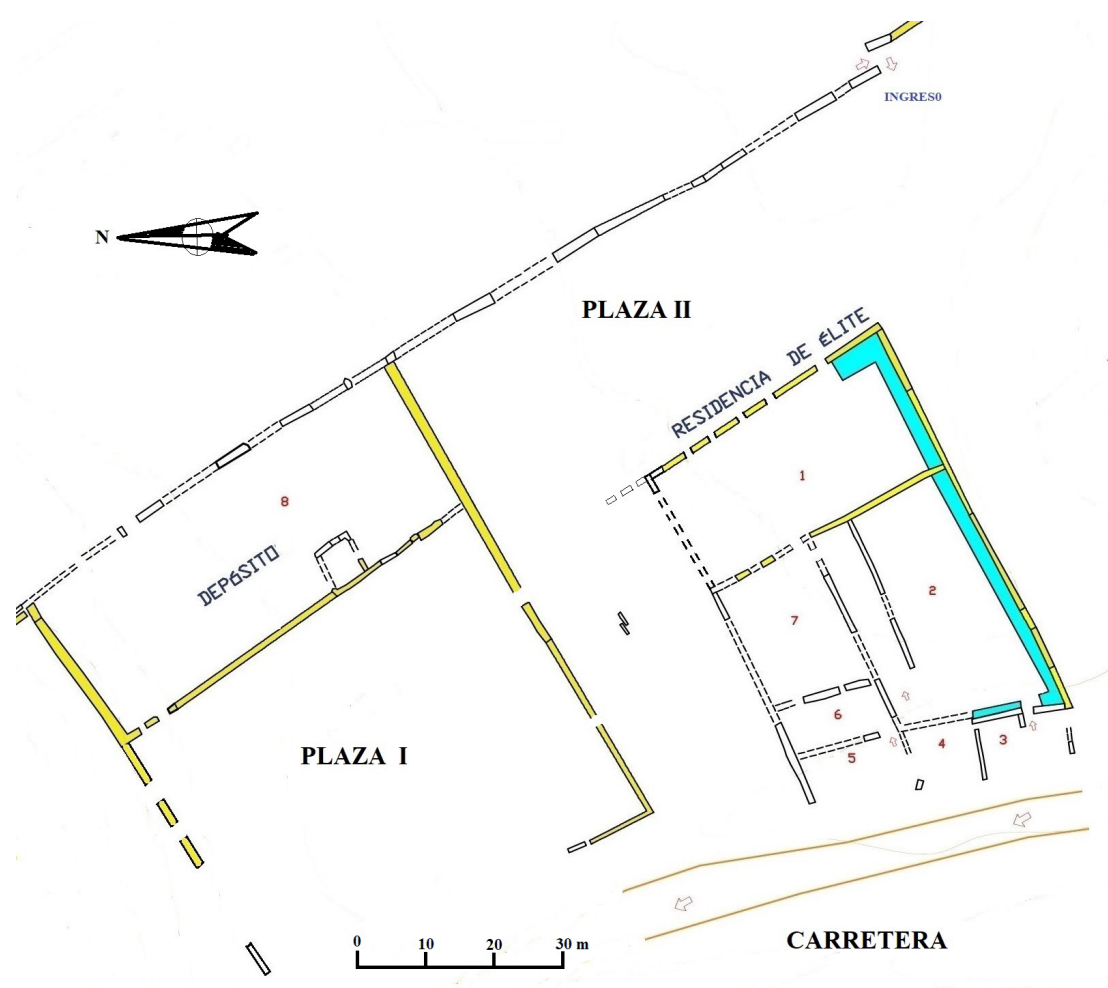

Figura 2. La residencia de élite inca de Cerro Respiro, asociada a las dos plazas 
A partir de la distribución las estructuras y espacios públicos, el sitio fue dividido en cuatro grupos de componentes arquitectónicos.

\section{Sector A}

Se ubica en la zona norte del asentamiento y en la parte más estrecha de la quebrada, está conformada por dos recintos relacionados a un espacio abierto (figura 1). Los ambientes son rectangulares con muros de más de $4 \mathrm{~m}$ de altura. Estos acondicionan espacios son amplios y por su forma parecen estar relacionados a áreas de actividad productiva. Los paramentos de los recintos son de tapial y no se aprecia restos de algún revoque o enlucido. El material constructivo es el barro con inclusiones de pequeñas piedras angulosas, cantos rodados y restos de moluscos.

Los muros presentan huellas de su construcción, es visible los paños o encajonamientos horizontales construidos sin el uso del molde, que consiste en construir los extremos laterales de los muros, luego las unidades intermedias, las que servían de topes o moldes dándoles las formas de trapecios con base ancha y acabado menor, logrando bloques horizontales de diferentes formas. Este tipo de construcción imita la técnica de la construcción inca de la sierra de grandes bloques de piedras, pero en este caso con distinto material constructivo como es el tapial. En este sector destaca el espacio abierto anexo a los dos recintos mencionados y permite el ingreso al área funeraria ubicada al lado noreste de la ladera del cerro, la plaza II y los recintos que conforman la residencia de élite.

\section{Sector B}

Se localiza en la zona suroeste del sitio, está compuesto por tres unidades funcionales distintas como son: un recinto rectangular alargado formado por la muralla y muros laterales ubicados en la ladera del cerro, así como muros destruidos ubicados hacia la zona de la plaza principal. Esta estructura en su interior contiene las bases de dos recintos cuadrangulares de $4 \mathrm{~m}$ de largo por $4 \mathrm{~m}$ de ancho y $1.40 \mathrm{~m}$ de altura. En uno de estos recintos se realizó excavaciones en el 2003, registrándose tres capas disturbadas de coprolitos de animales y una cuarta capa más profunda relacionada a un piso de barro compacto con restos de corontas de maíz y arena, lo que permitió inferir una función de depósitos para almacenar productos agrícolas (Ayala, 2008).

La plaza I, es un espacio rectangular de $52 \mathrm{~m}$ de largo por $34 \mathrm{~m}$ de ancho que articula todo el conjunto de estructuras del sitio y debió ser el espacio público donde debieron concentrarse la población en relación a las principales actividades públicas y religiosas. Este espacio público se encuentra asociado al camino que se dirige a Puente Inca y la proyección del camino que se prolonga por la carretera con dirección al mar.

Una tercera unidad funcional del sector, es el área funeraria que se ubica en el lado Oeste de la plaza en terreno de ladera de cerro, en este lugar se encontró parte del cementerio del sitio, su estado de conservación es ruinoso debido a que 
las tumbas ubicadas en este espacio fueron saqueadas. En este lugar han quedado expuestos contextos funerarios abiertos en donde se pudo identificar tumbas en fosa con techo de madera conteniendo fardos envueltos en textiles y soguillas de fibra vegetal, restos funerarios en posición flexionada y osamentas humanas dispersas (Ayala, 2008).

\section{Sector C}

Se sitúa al sureste del sitio, constituye el sector más importante y está conformado por siete recintos, por sus características y evidencias halladas en las excavaciones arqueológicas fue definida como área residencial de élite asociada a una autoridad politica, al cual se accede por una entrada principal ubicada el lado sureste del sitio. Este edificio está compuesto por dos niveles de plataformas, un patio central con banquetas laterales a manera de audiencia, un pasadizo que comunica a un conjunto se recintos privados y una estructura rectangular asociada a la plaza II (figuras 1 y 2).

En cuanto a la plaza II, esta tiene la forma rectangular alargada orientada de sur a norte, ocupa un área de 1,700 $\mathrm{m} 2$ delimitada por la muralla y recintos de la residencia de élite. En la superficie de la plaza se identificó contextos funerarios disturbados, lo que indicaría una función ceremonial. Es parte del sector, un recinto rectangular de muros altos de tapial en tres de sus lados contiene banquetas laterales en forma de "L". Excavaciones en este recinto (R-1) en el 2003, se registró restos de dos fogones asociados a un piso con material cultural como cerámica del estilo inca local y en la banqueta, un artefacto lítico roto (porra circular) en proceso de elaboración. El artefacto más importante registrado en este recinto es un quipu de algodón de color blanco y marrón dividido en dos partes con nudos de diversas formas (figura 3), hallado en el piso del recinto con material cultural inca.

Las evidencias culturales asociadas a esta estructura corresponden a actividades domésticas de preparación de alimentos asociadas a un fogón, así como restos de actividades de consumo de alimentos asociados a un piso que funcionó en la época inca. Considerando la construcción del recinto y las evidencias culturales identificadas y su asociación directa con la plaza II, este ambiente habría sido usado como un posible recinto de vivienda o de alojamiento.

Respecto al patio central (R-2), este tiene la forma trapezoidal, se trata de la audiencia de la residencia de élite, lo conforman muros adosados de gran tamaño que le da un aspecto monumental y único en el sitio, los muros de este recinto acondicionan un espacio amplio que es articulado por medio de un pasaje que comunica a los recintos anexos. El pasadizo tiene $32 \mathrm{~m}$ de largo por $5 \mathrm{~m}$ de ancho y presenta muros bajos, los cuales debieron alcanzar mayor altura y debió presentar una cubierta ligera. 


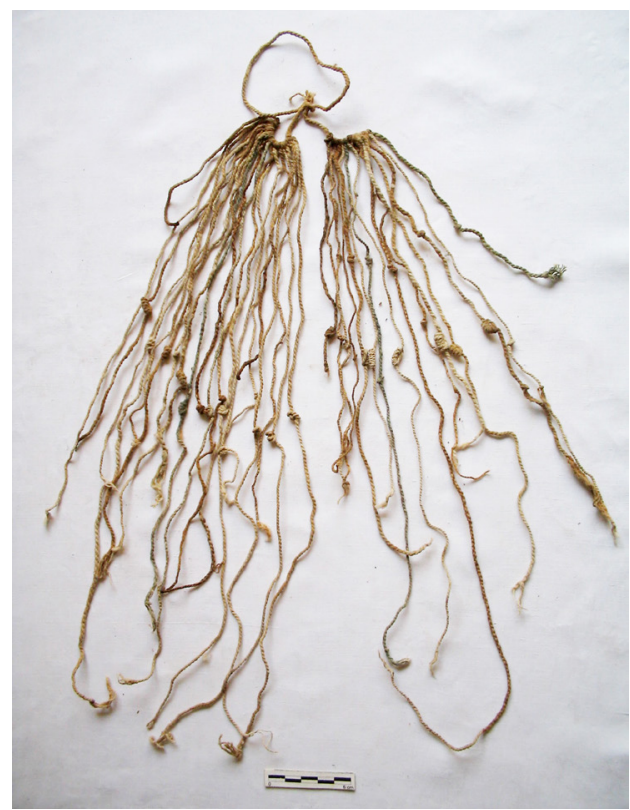

Figura 3. Cerro Respiro, detalle de un quipu inca, hecho de hilos de algodón de color blanco y marrón. Recinto1, de la residencia de élite. Unidad 20, capa 3.

Las excavaciones en el patio central han evidenciado dos tipos de muros asociados a dos periodos de ocupación. Los muros del Período Intermedio Tardío se caracterizan por ser de mayor espesor y de paños más cortos, la elevación del muro consiste en encajonamientos laterales de diverso tamaño rellenados con gravilla y barro, sellados por una capa de barro, los encajonamientos fueron de $1 \mathrm{~m}$ de ancho alternados con piedras angulosas cubiertas por barro y restos de moluscos. En cambio, los muros de tapial de la época inca se caracterizaron por ser más delgados, son de paños horizontales y verticales con un mejor acabado.

El patio central de la residencia de élite presenta rasgos arquitectónicos únicos a los demás recintos del sector, estas son las hornacinas de forma rectangular alineadas en sentido horizontal, un vano clausurado que guarda relación con los recintos de una ocupación anterior y evidencias de postes, hoyos alineados y distribuidos de forma horizontal en la plataforma de los muros adosados, que por sus características corresponden a hoyos de postes que habrían soportaron el techo de la audiencia.

Son parte de este espacio dos banquetas asociadas al piso (capa 3), que contenía contextos de desechos orgánicos, fragmentos de cerámica del estilo inca, una ofrenda de Spondylus con cuentas de espingo asociada a la banqueta y los muros construidos en la época inca (figura 4), así como dos vasos de madera fragmentados con diseños geométricos del estilo Inca, evidencias culturales que indicarían que el recinto fue destinado a la recepción de personas, agasajos y banquetes. 


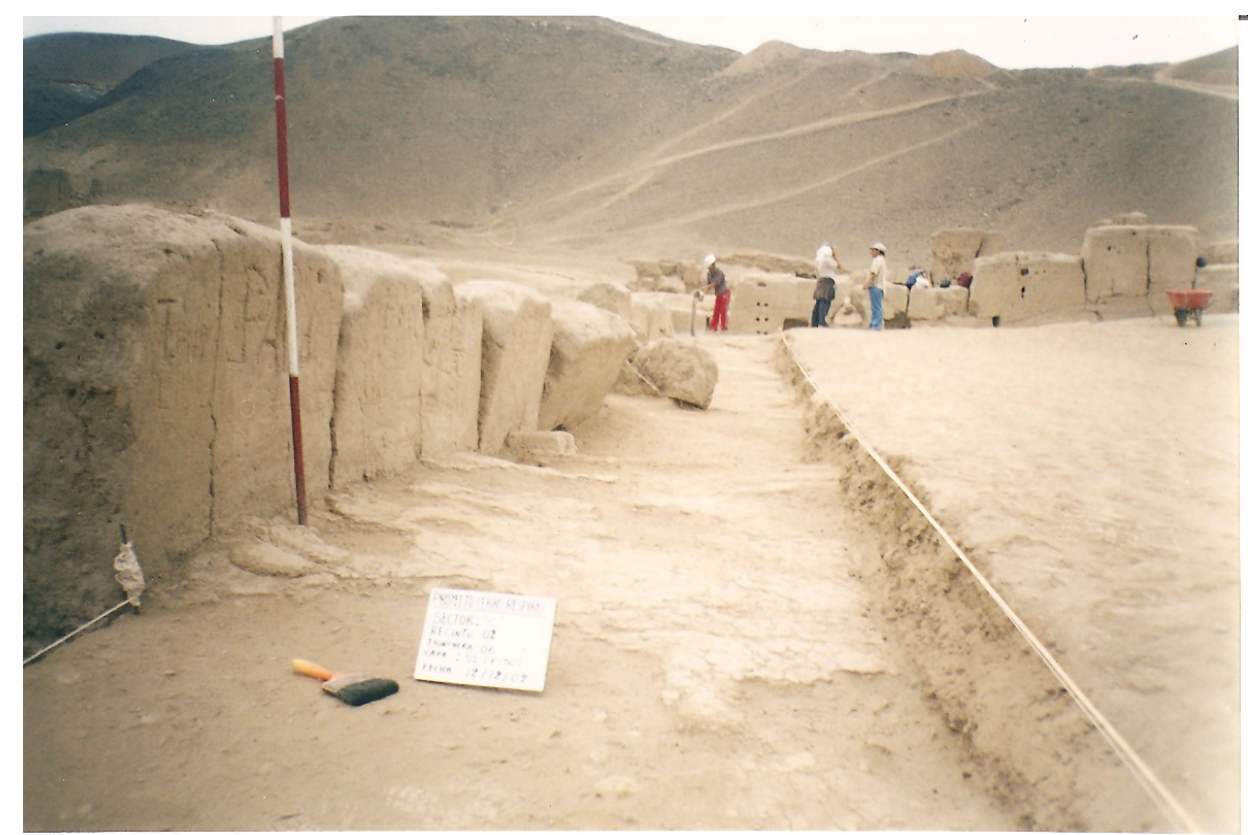

Figura 4: Excavación Unidad 6, detalle del piso capa 3 en el patio central de la Residencia de élite.

En cuanto a los recintos anexos (R-3, 4, 5, 6 y 7) son de planta cuadrangular y rectangular, se encuentran ubicados en un nivel inferior y lateral al patio central y se encuentran parcialmente cortados por la construcción de la carretera. Estos recintos son espacios confortables y por su forma debieron funcionar como vivienda del gobernante inca (curaca). Excavaciones en el recinto contiguo al pasadizo (R-7) se recuperaron parte de un contexto funerario disturbado que contenía restos de textiles con diseños inca y ofrendas de vasijas del estilo inca local. En cuanto a los textiles son una bincha con diseños de rombos horizontales y diseños de figuras escalonadas de color amarillo, rojo y negro que terminan en flecos (figura 5). El otro textil es un tapiz hecho de lana con decoración de peses y aves estilizadas que combina colores rojo violáceo, amarillo, negro y banco (figura 6).

Las evidencias identificadas en el recinto (R-6) también importantes destacan dos moldes de cerámica fragmentada y restos de pigmentos de color rojo en dos pequeñas bosas de cuero de camélido de color blanco y negro (figura 7), ambos hallazgos fueron identificados en la capa 4 de la unidad 22 y estarían relacionadas a actividades productivas. Forma parte de este sector, el área funeraria ubicada en la ladera del cerro lado este del sitio, el mismo que fue destruido parcialmente cuando se construyó la carretera. 


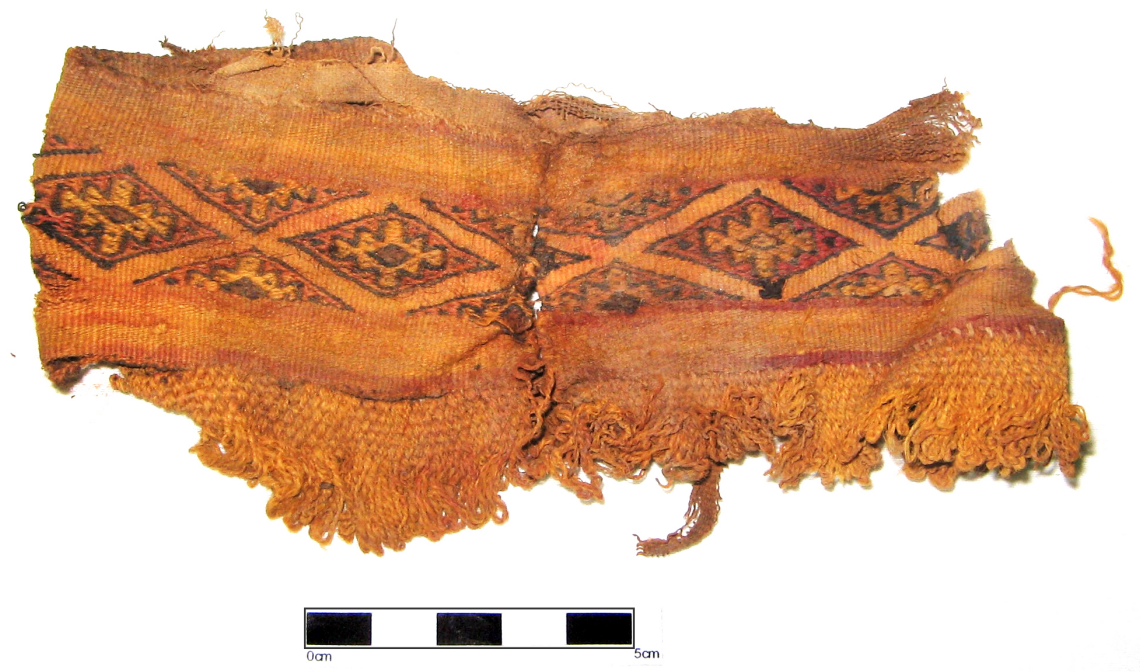

Figura 5. Textil inca, bincha de color amarillo, negro y rojo, con diseños escalonados y rombos. Unidad 8, capa 4. Recinto 7 de la residencia de élite.

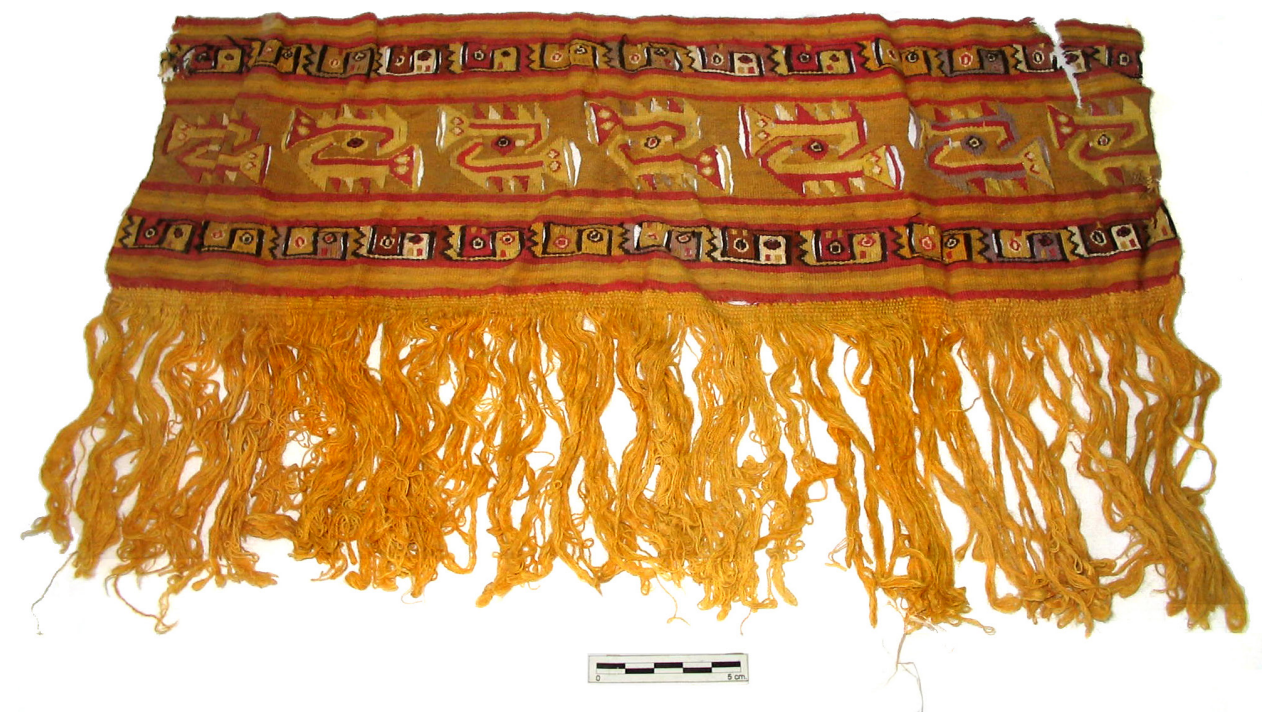

Figura 6. Textil de lana, estilo Inca, técnica del tapiz con flecos, con diseños geométricos de grecas horizontales, peces y aves estilizadas que combinan colores, amarillo, rojo negro y blanco. $U-9$, capa 2 , recinto 7 . 


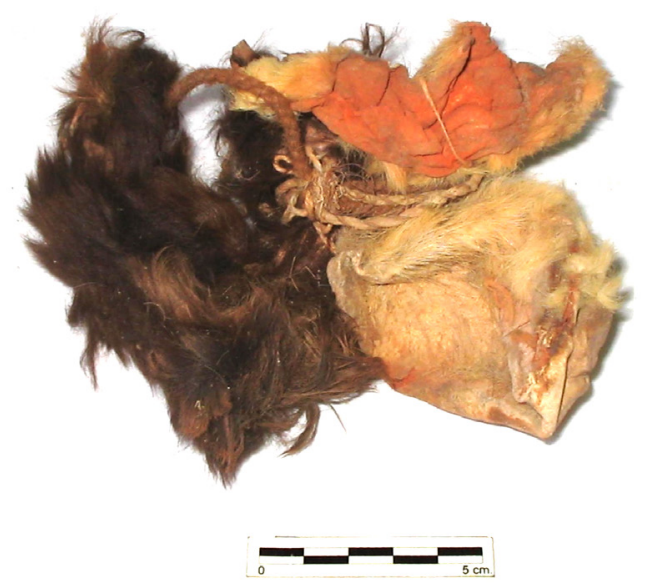

Figura 7. Bolsas de cuero conteniendo pigmento rojo. Unidad 22, capa 3, recinto 6 de la residencia de élite.

\section{Sector D}

Se ubicaba hacia el lado noreste, la ladera baja del Cerro Respiro, en la actualidad esta área es ocupada por el Asentamiento Nueva Esperanza de la jurisdicción del distrito de Puente Piedra. Según la fotografía aérea del año 1945, en este lugar existían estructuras ortogonales asociadas a una plaza y recintos de menor tamaño hechos de tapial, así como un segmento de muro que unía al camino inca y la zona de Puente Inca (figura 1). En el reconocimiento del año 2003 en este lugar, sólo existía, un muro de la plaza cuadrangular y restos de tumbas disturbadas, por lo que las evidencias arqueologías en este sector ya no existen.

Asimismo, las prospecciones en el valle bajo del Chillón permitieron identificar residencias de élites como es el caso de los sitios Palacio Oquendo y Tambo Inca, las mismas que comparten elementos arquitectónicos similares a los identificados en el sitio de Cerro respiro y que en los siguientes párrafos describimos.

\section{PALACIO OQUENDO}

Se localiza en la margen izquierda del río del Chillón, en el valle bajo, lado sur y falda del Cerro Oquendo. El asentamiento está conformado por un conjunto de veinticuatro recintos de planta rectangular y trapezoidal, distribuidas en un área de 3.5 hectáreas, asociado al camino inca que cruza por el sitio en dirección suroeste. El espacio construido más importante comprende una estructura trapezoidal organizada alrededor de cuatro patios o espacios públicos conectados por un vano principal restringido (muro cortina) que permite el ingreso desde el camino y un pasaje estrecho que comunica a ambientes más privados. 
Según las investigaciones de Ayala (2008) el sitio presenta tres componentes arquitectónicos diferenciados en cuanto a la distribución de los recintos.

El sector I: se localiza a 50 metros al noroeste del sector principal, al pie del Cerro Oquendo, se trata de una estructura de planta rectangular parcialmente destruida hecha de tapial sobre una zona rocosa, el recinto tiene 60 metros de largo por $24 \mathrm{~m}$ de ancho y un muro divisorio en la parte lateral (figura 8). El espacio fue construido excavando y nivelado la ladera del cerro para lograr un espacio amplio, donde se observa la cabecera de los muros laterales y otros muros destruidos junto a la acequia de regadío. Por la ubicación y forma habría correspondido a una estructura de alojamiento tipo kallanca inca.

El sector II, corresponde a la Residencia de Élite, está conformado por dieciocho estructuras de planta ortogonal organizadas alrededor de una plaza central, interconectada por dos pasadizos. Uno de ellos tiene forma de zig zag, se ubica en el extremo noreste de la plaza y permite el ingreso directo a dos recintos privados. El otro acceso, se localiza en el lado suroeste del sector, se trata de un vano de ingreso ciego que presenta como característica un muro cortina, espacio por el cual se accede a un patio y a tres recintos rectangulares que se encuentran relacionados con el vano de ingreso.

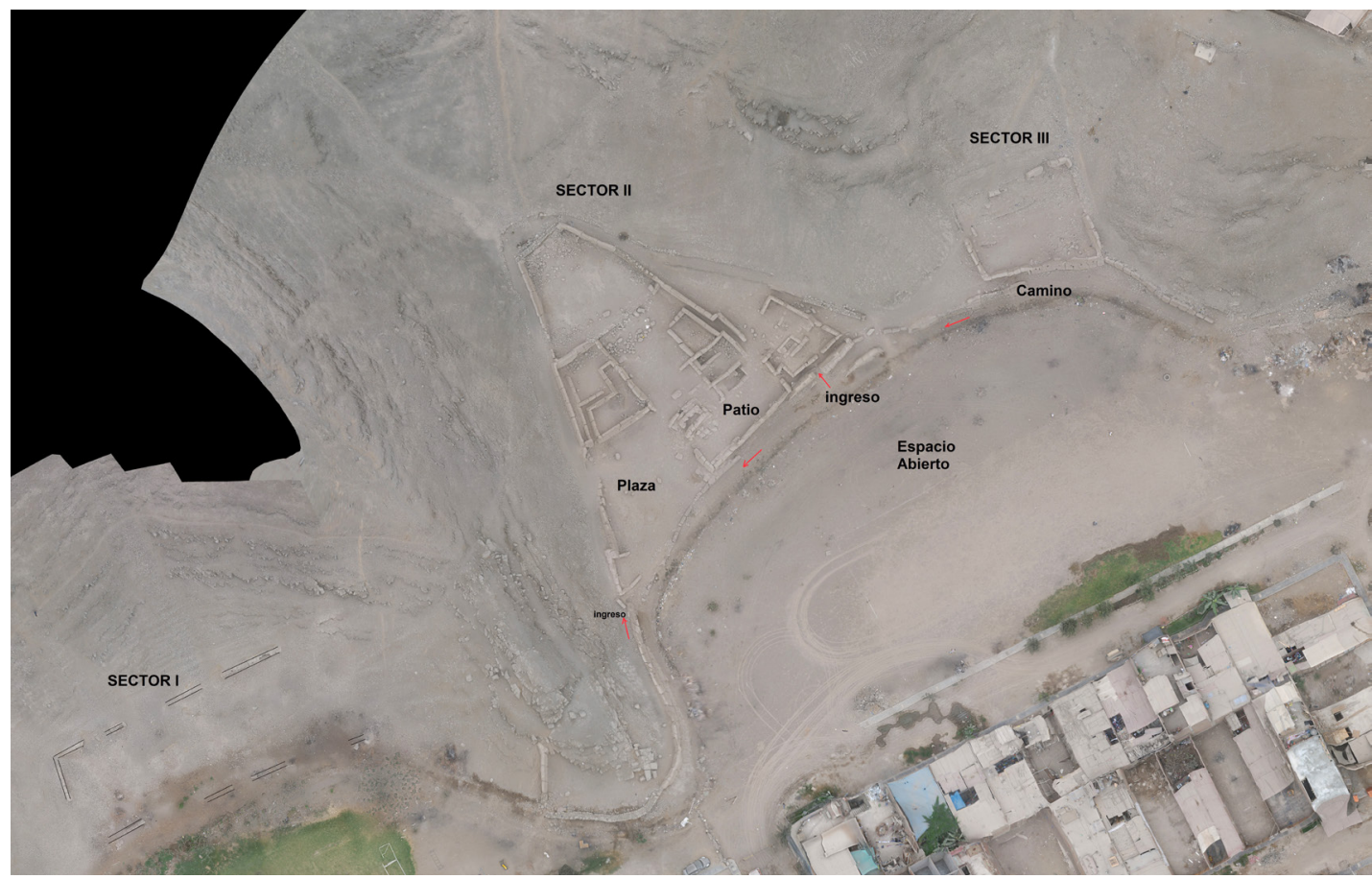

Figura 8. Palacio Oquendo, detalle de los tres sectores, la composición arquitectónica de la residencia de élite asociada al camino inca. 
El patio tiene muros de tapial de gran altura, presentan restos de enlucidos y pintura amarilla, por su forma corresponde a una sala de recepción por la cual se accede a un pasadizo angosto de $80 \mathrm{~cm}$ de ancho con muros escalonados y de $2 \mathrm{~m}$ de alto, prolongándose a un pequeño patio y a tres recintos reservados laterales (figura 8).

Es parte del sector, una unidad funcional ubicada a la entrada principal del sector compuesta por estructuras que se ubican hacia el lado suroeste. Se trata de una estructura trapezoidal tipo apéndice dividida por muros cortos que acondicionan espacios diferenciados de planta cuadrangular y rectangular, en la estructura de mayor tamaño se localizan estructuras cuadrangulares que parece corresponden a depósitos domésticos construidos con adobes, similares a los registrados en el sitio de Tambo Inca. La distribución de los recintos asociados al patio, la plaza y los pasadizos evidencian un espacio reservado de vivienda residencia de élite (curaca) que debió tener a su cargo la producción y administración de productos agrícolas de del mar requeridos por el imperio inca (Ayala 2008).

El Sector III, se ubica a $50 \mathrm{~m}$ de distancia hacia el lado sureste del sector II junto al camino y en terreno inclinado de ladera del Cerro Oquendo, lo conforma una estructura de planta trapezoidal cercada con muros y un vano de ingreso lateral hacia el lado oeste, contiene en su interior tres plataformas a desnivel mediante muros de baja altura asociados al vano de ingreso. Por su ubicación y forma, estos muros de contención o plataformas evidencian una posible área de trabajo o zona de secado de productos, área relacionada a actividades productivas.

\section{TAMBO INCA}

Otro de los sitios analizados es Tambo Inca, ubicado en el valle bajo margen derecha del río Chillón distrito de Puente Piedra, se emplaza en la cima de un pequeño montículo rocoso natural de forma alargado, en este lugar se construyeron un conjunto de recintos agrupados en siete agrupamientos o sectores, divididos por calles transversales, protegidos por un muro perimétrico ubicado hacia el lado Este y asociado a un espacio público o plaza localizado hacia el lado Oeste del sitio (figura 9).

Las unidades arquitectónicas que lo conforman son construcciones hechas de tapial, en algunos casos combinados con adobe. Los bloques de estructuras son de planta ortogonal y se encuentran asociadas a patios articulados desde el espacio abierto exterior.

El análisis arquitectónico del sitio ha permitido identificar el edificio residencial de élite en el sector III ubicado en el lado noroeste de la plaza central, lo conforman 12 recintos de planta ortogonal (figura 9), asociados a un patio central, articulado por un pasaje que comunica desde la plaza principal. La residencia tiene un diseño tipo cancha. Hacia el lado oeste del patio se ubican seis recintos asociados al ingreso 


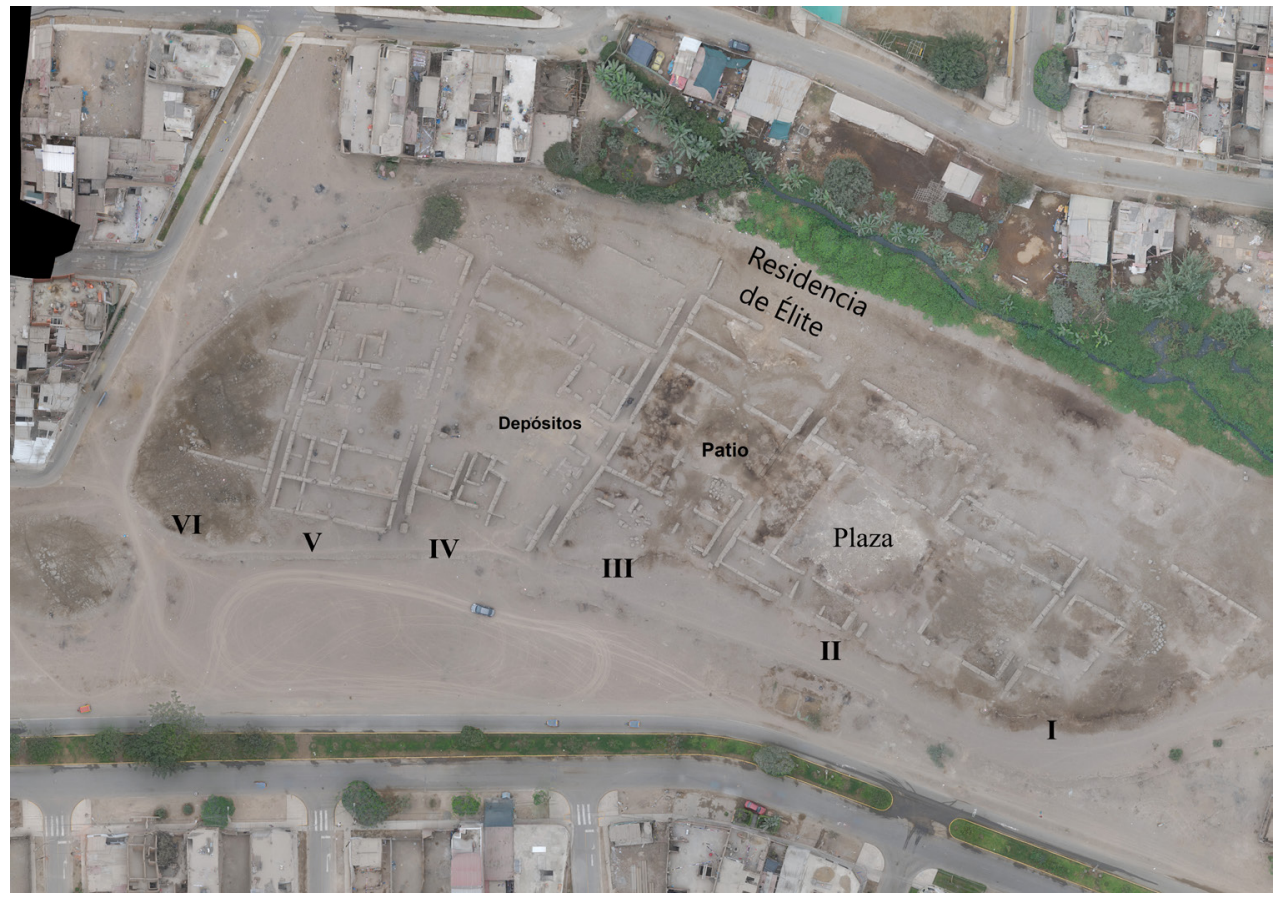

Figura 9. Tambo Inca, detalle de la residencia de élite en el sector III, asociada a la plaza central y el área de los depósitos.

a través de un recinto y no mediante un pasadizo directo como en los demás sectores. Este sector, al igual que los anteriores, se encuentra separado por un pasadizo o calle de $2.30 \mathrm{~m}$ de ancho y $3 \mathrm{~m}$ de altura. El patio de este edificio comunica directamente con el pasaje y el segundo sector, mostrando así su estrecha relación entre ambos, las características arquitectónicas de recintos amplios y de buenos acabados habrían albergado a un posible gobernante en Tambo Inga.

El diseño arquitectónico del sitio Tambo Inca muestra una clara organización funcional de arquitectura inca, así como el uso de los materiales y técnica constructiva de la tradición local, detalle que fue identificado en los sitios de Cerro Respiro y Palacio Oquendo (Ayala 2008). En el caso de Tambo Inca, es observable el diseño tipo cancha, a través de la construcción de muros perimétricos y luego se adosaron otros de menor espesor en el interior, para luego construir recintos cuadrangulares o rectangulares alrededor de un patio central. Los vanos de ingreso parten siempre desde el exterior y permiten el ingreso al patio de cada sector y de este a otros ambientes privados.

A partir del análisis de la arquitectura y cultura material, el sitio de Tambo Inca este tiene una ocupación desde el Período Intermedio Tardío hasta la época Colonial, en la que se observa remodelaciones con adobes a través del estilo Inca sobre arquitectura de un periodo anterior y ocupación durante la Colonia. 
La función del sitio ha sido definida por Dillehay (1997, p. 400) y Agurto (1984, p. 61-62), como un centro administrativo, lugar de alojamiento y paso de personal militar. Sin embargo, su ubicación entre los caminos del Rímac con dirección a Ancón y el camino Inca localizado siguiendo el cauce del río hacia el valle alto del Chillón, indican que el sitio tuvo un control estratégico sobre los recursos humanos y naturales en esta parte del valle (caso de Palacio Oquendo, Cerro respiro y la Fortaleza de Collique). Ubicados en las zonas de entrada y salida del valle. Su complejidad y diseño evidencian también sectores asociados a distintas actividades como el de acopio y transformación de productos como el sector IV del sitio donde se ubican los depósitos.

La plaza central ubicada en el sector II, es también un espacio representativo del sitio, este espacio público es de planta rectangular y ocupa $2,234 \mathrm{~m} 2$, dividida en dos espacios a desnivel, orientada de sureste a noroeste y asociada a una estructura lateral de forma rectangular tipo una kallanca con acceso a la plaza donde se ubican paramentos ron restos de hornacinas rectangulares.

\section{RESIDENCIAS DE ÉLITE INCA}

Las crónicas han permitido identificar dos tipos de palacios construidos por los incas, los construidos por los incas en el Cusco organizados alrededor de la plaza Haucaypata y las residencias palaciegas construidas y mantenidas por los incas en territorios conquistados fuera del Cusco. En el caso del Cusco, los palacios estaban relacionados con áreas públicas, áreas privadas de residencia y áreas productivas. (Gasparini y Magnolies, 1977, p. 57-58).

Estos edificios fueron muy importantes ya que eran la morada de los gobernantes incas. La información más completa sobre este tipo de edificio llamado palacio inca es proporcionada por Morris (2016), quien reconstruye a partir de la información del cronista Martin Murúa (1946[1590-1609]. p.165-166), las características de los palacios inca y señala que: los palacios del Cusco contenían dos puertas o portadas muy elaboradas con servicio de guardias, cada portada comunicaba a un patio espacioso (plazas), con acceso de personas a varios sectores del complejo arquitectónico y edificios residenciales usados por el inca. Y que esta estructura arquitectónica expresaba una jerarquía espacial de dos partes, un rol político en relación a la estructura de las Panacas reales y el mantenimiento de esta propiedad por parte del estado (Morris, 2016, p. 224-225).

Ante la imposibilidad de identificar y describir los palacios observados por los cronistas del siglo XVI, los arqueólogos se han interesado en los centros administrativos fuera del Cusco para identificar y evaluar los "palacios" construidos por los incas en territorios conquistados, como es el caso de Huanuco Pampa en Junín (Morris (2016), Centinela en el valle de Chincha y Tambo Colorado (Morris (2016, 
p. 224-225), el sitio de Incahuasi en Cañete (Hyslop, 1985) y la residencia de élite de Tauri Chumbi en Pachacamac como posible residencia de un gobernante inca (Hyslop, 2017. p. 311-312).

Por lo tanto, debemos preguntarnos si las distintas estrategias aplicadas en territorios conquistados, reflejan situaciones distintas y estas a su vez influyeron en las construcciones de diversos tipos de asentamientos que varían tanto en sus diseños arquitectónicos, como sus tamaños y funciones.

Producto de los reconocimientos arqueológicos realizados en el valle del Chillón en el 2008 y el 2016, se identificaron distintos tipos de asentamientos con ocupación Inca, siendo los más representativos las residencias de élites del sitio Cerro Respiro, Tambo Inca y Palacio Oquendo, todos estos edificios asociados a la red vial Inca que comunica la costa con la sierra central, sitios que evidencian un nivel de organización administrativo y político relacionada con la organización planificada por parte del Estado a partir de la construcción de palacios, el control directo de los recursos naturales y aprovechamiento de la mano de obra de las poblaciones dominadas.

Según las investigaciones llevadas a cabo por Eeckhout y Farfán (1999); Eeckhout, (2004), las pirámides con rampa de Pachacamac fueron residencias palaciegas de los señores Ychsma durante el periodo Intermedio Tardío, muchas de las cuales fueron ocupadas durante el horizonte tardío, siendo los equipamientos arquitectónicos, el patio, las rampas, la audiencia, ambientes de vivienda, aéreas relacionadas a actividades domésticas, patios, plazas y en algunos casos depósitos.

Para el valle del Rímac, Villacorta $(2003 ; 2004)$ sostiene que la arquitectura de poder durante el Intermedio Tardío estuvo ligada a un tipo particular de edificio, (residencia de élite o palacio), con una arquitectura como símbolo distintivo de poder político de las élites gobernantes durante el Horizonte Tardío.

Mackey (2003) al investigar el sitio de Farfán demostró que los Incas transformaron completamente la organización social en el sitio, mediante la construcción de nuevas residencias de élite sobre la ocupación Chimú, espacios asociados a ocupaciones de personajes de rango y a actividades específicas. Id. (2003) sugiere a su vez que los criterios usados para determinar los rasgos de las residencias de élite se basan en 3 grupos de variables: La primera comprende el tamaño total de la residencia, el número de recintos, su organización espacial, y la diversidad de funciones al interior de un conjunto de recintos. La segunda variable tiene que ver con la seguridad y protección ofrecida por la residencia y la tercera variable serian los materiales y técnicas de construcción de las residencias de élite (Ibid. 2003, p. 325).

De lo expuesto y las evidencias halladas en el sitio de Cerro Respiro, Palacio Oquendo y Tambo Inca se puede considerar que las residencias de élite o palacios fueron construcciones diferentes a las viviendas de la población común, cuya función tiene que ver con la residencia de un señor local y también con funciones pú- 
blicas, directamente relacionado al control político y la administración, siendo los patios centrales y las plazas los espacios para reunir a la población en actividades rituales y para redistribución de bienes.

Considero que la identificación y en la explicación de las residencias de élite o palacios deben considerar ciertas características arquitectónicas como: el diseño planificado del sitio, equipamiento arquitectónico palaciego conformado por recintos asociados a un patio central o audiencia que contiene banquetas laterales para sentarse conectados por pasadizos, que comunican a espacios reservados de vivienda, espacios públicos (patios y plazas), ambientes para almacenamiento de productos (depósitos), tendales o secaderos y áreas funerarias. Así como, criterios de seguridad, como estructuras de protección, ingresos restringidos, diferenciados de otro tipo de estructuras con materiales constructivos seleccionados, técnicas y mejores acabados de construcción al momento de ser edificados.

Además, contienen habitaciones domésticas que pueden estar aisladas o formar parte de la residencia de élite, en algunos casos puede estar contigua o adyacente a la unidad residencial. Es decir, elementos materiales que evidencien la realización de una actividad relacionada a la satisfacción de una o varias necesidades individuales o sociales. Por otro lado, se debe considerar la unidad residencial como espacio equivalente a una vivienda, habitación donde un individuo que habita temporal o permanentemente. Desde esta perspectiva considero que la residencia de élite no es una estructura aislada, sino es sobre todo un espacio planificado e impuesto por los incas como un modelo de construcción destinado a una autoridad y que debió cumplir funciones políticas y administrativas en el valle bajo del Chillón.

\section{LA ADMINISTRACIÓN INCA}

Para poder entender la administración inca consideramos que es necesario definir que es territorio y territorialidad. En el caso del primero hace referencia a la jurisdicción o espacio físico de una comunidad, región, un espacio geográfico humanizado. En el caso del segundo, implica una noción de política relacionado al uso del espacio como vehículo para el ejercicio del poder, que implica, como se implantan las estrategias espaciales, organizan, dividen, se controlan los espacios y personas y como se apropia o controla un territorio conquistado (Sack,1983, p. 58-60).

En el caso del valle del Chillón, asemos uso de estos dos conceptos para evaluar y comprender la administración inca en el territorio del valle bajo del Chillón, una de ellas, es la estrategia llevada a cabo por los incas a través del mecanismo de la guerra y una segunda etapa de consolidación y control de una economía de dominio directo a través de un repoblamiento de grupos étnicos aliados al imperio inca, asentados en zonas clave del valle en la producción de bienes económicos de interés estatal. 
La administración como mecanismo de imposición de un sistema político centralizado y de control territorial fuera del Cusco, les permitió a los incas lograr la unificación de diversos grupos a través de la movilización de una compleja economía mediante el manejo y la manipulación de una amplia gama de interacciones (Morris, 2003, p.134). La imposición de un sistema administrativo en las sociedades dominadas, produjeron cambios drásticos en los sistemas políticos de los grupos subyugados (D'Altroy, 2015, p. 277).

Según lo planteado por Morris (2003) para la sierra central, los incas construyeron ciudades incas (centros administrativos) de reproducción estatal planificados por el imperio los cuales servían como espacios de concentración de población sometida, según las necesidades económicas y políticas de esta región. Es decir, los centros administrativos de mayor tamaño parecen haber sido la ciudad principal de una "provincia inca", construida para organizar un territorio conquistado.

Es decir, en cada "provincia inca" existía una ciudad capital que funcionó como centro administrativo o religioso que controlaba un amplio territorio que incluía uno o varios valles y en estos centros administrativos se construyeron palacios, templos plazas ushnus y Acllahuasis. Esta forma de organización de grandes centros administrativos regionales habría sido el caso de Pachacamac en la costa central (Cobo, [1653]1983).

Para el caso del sitio arqueológico Cerro Respiro, se trata de un asentamiento inca pequeño, sin embargo, contiene algunos edificios de los grandes centros administrativos. Por tanto, las evidencias de la cultura material identificadas como la arquitectura y contextos excavados nos llevan a varios cuestionamientos que requieren ser explicados, una de estas preguntas es ¿cuáles son los tipos de edificaciones que los incas construyeron en Cerro Respiro?, ¿Cuáles son sus características arquitectónicas? y ¿Con que fines los incas las construyeron?, Si bien son preguntas amplias y complejas de ser respondidas, trataremos hasta donde sea posible a partir de evidencias arqueológicas brindar una explicación a dichas interrogantes

Las excavaciones llevadas a cabo en el sitio han reportado nuevos datos permiten explicar al respecto, estas evidencias arqueológicas confirman instalaciones destinadas a actividades de una zona residencial de élite, donde se hallaron restos culturales asociados a los pisos de la vivienda donde habría habitado el curaca local.

Las evidencias indican que el sitio durante el Período Intermedio Tardío comprendía un espacio más reducido entre la muralla y el sector C. Compuesto por estructuras ortogonales en menor número, construidas con muros de tapial de gran espesor identificados en los recintos 2, 6 y 7, los mismos que funcionaron como ambientes de vivienda asociados a las plaza I y II lo que parece indicar que durante este período fue un asentamiento importante, el mismo que estuvo protegido por 
la muralla que bordea la quebrada y el lado Oeste. La cultura material hallada corresponde al estilo Ychsma Tardio y estilo Chancay que fueron recuperados de los estratos más profundos de la unidad de excavación 2 (capa 4 y 5) y guardan relación con este periodo.

Durante el Horizonte Tardío, el sitio Cerro Respiro tuvo un crecimiento horizontal, se construyeron nuevos ambientes, fuera de la muralla como el área de los depósitos, las dos plazas fueron modificadas y se construyeron como los recintos 9 y 10 los mismos que fueron amurallados (figura 2).

De igual forma los incas reconstruyeron y modificaron mediante rellenos constructivos el edificio residencial de élite con la finalidad de elevar y acondicionar un espacio para construir el patio central mediante la construcción de muros más delgados adosados a estructuras antiguas, que se manifiesta en la capa 3, piso de barro compacto asociado a cultura material del estilo inca local y elementos constructivos relacionados a las dos banquetas laterales (figura 2). Asociado a este tipo de construcción y remodelación dela residencia se encontró una ofrenda de Spondylus sp., conteniendo cuentas de espingo que evidencian un contexto ritual de sello y clausura de un ambiente anterior y la construcción de un nuevo espacio durante la ocupación Inca (figura 10).

Las construcciones adyacentes a la residencia de élite son las dos plazas asociadas tanto al sector B como al sector C, espacios públicos donde se realizaron posiblemente actividades públicas como religiosas. Excavaciones en la plaza I, repor-

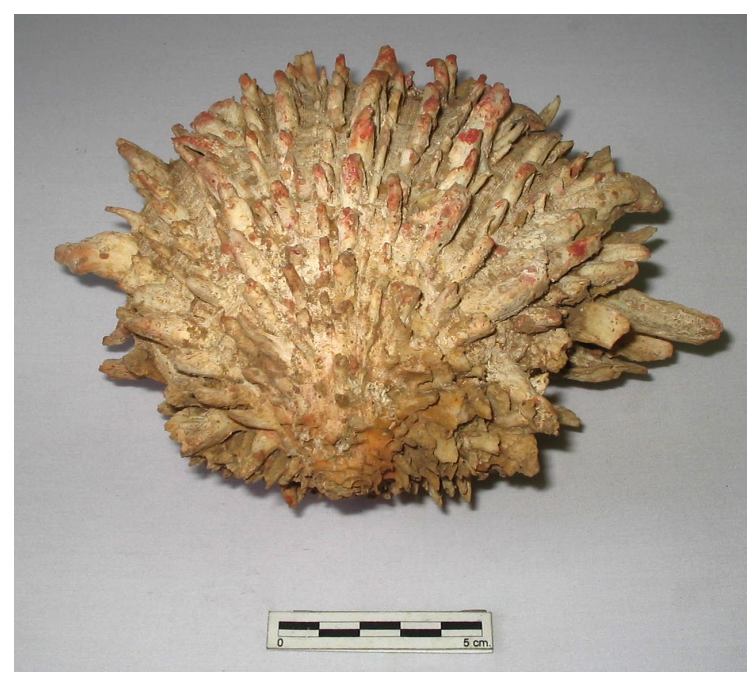

Figura 10. Ofrenda de Spondylus asociado a la clausura y construcción de la banqueta y piso del patio central de la residencia de élite, lado sur oeste de la Unidad 2, capa 3. 
taron evidencias de un piso compacto muy deteriorado asociado a gran cantidad de desechos orgánicos compactos, fragmentos de cerámica doméstica, ollas con restos de hollín, fragmentos de vasijas grandes (tinajas), restos óseos de animales (llama, cuy), pescado y restos de moluscos, lo que confirma que fue un espacio público fue importante, donde se habrían llevado a cabo eventos políticos, rituales y tal vez festivos.

El sector C del sitio expresa una función distinta contiene ambientes muy elaborados desde donde se pudo ejercer el poder secular Inca. Se caracterizan por disponer de un patio o audiencia, lugar de recepción, donde se realizaron al parecer reuniones, banquetes políticos, consumo de alimentos y bebidas. En este ambiente asociado al piso (capa 3) se encontró dos vasos de madera (Queros) con diseños de estilo Inca.

Sobre las reuniones de los curacas con los súbditos Tom Dillehay (2003) menciona que los señores incas tenían obligaciones recíprocas de hospitalidad y generosidad en lo que concierne a productos alimenticios y bebidas, estos productos sirvieron para mantener las relaciones de reciprocidad entre los gobernantes y gobernados. De igual forma en la visita hecha a Guancayo, Maca y Guaravni en 1571 por Juan Martínez Rengifo en el valle medio del Chillón, se menciona sobre los tributos y servicios que daban los indios de este repartimiento a las instituciones del Estado Inca, sobre ello Espinoza (1963, p. 56) describe:

[que cada pachaca que eran nueve, le daban al dicho inca cada año cinco cestos de coca, veintiséis pilas de ropa de algodón la mitad de hombre y la mitad de mujer y mas dos piezas de cumbi galanas, mas tres hanegas de maíz, mas cuatro cestos de ají grande, mas veinte pares de hojotas, diez petacas de pájaros secos hechos charqui, cinco petaquillas de zuara de coca para el inca, dos petaquillas de camarones secos, tres petaquillas de guabas secas, mas diez pares de rodejones de palo para las orejas del inga, una manta galana para hamaca-y que para el sol le tenían hecha una huertecilla de coca verde la cual cortaban y se la llevaban a ofrecer y quemar al dicho sol-y que para las mamaconas del ynga daba cada pachaca cada año diez pocchas de maíz-diez pocchas de frijoles, diez ollas grandes y chicas, cinco cargas de algodón por hilar- y en dicho repartimiento tenían en guarda trescientas cabezas de ganado de la tierra del ynga-asi mismo les llevan sapallos yuca y ají - de todo este repartimiento daban tres indios valientes hijos de los tres caciques para servicio del inca y otros tres indios para guardar servicio a las mamaconas y que de todo el repartimiento daban diez indias hermosas y escogidas para mamaconas del inca].

El relato no sólo explica detalladamente el tributo de productos elaborados que eran entregados al Inca, sino también sobre los recursos que tenia acceso el estado inca para el mantenimiento de estas instituciones. En este sentido, era necesario contar con una mano de obra suficiente para el trabajo en los terrenos de cultivo destinadas al Inca, para los curacas locales y las mamaconas. 
En el valle del Chillón después del dominio Inca, se expropió las tierras de los cocales de Quivi y ordenó que fuesen cultivadas por mitmas, entre ellos gente de Huarochirí y Canta (Rostworowski 1992, p. 240 -242). Todo hace suponer que las tierras de cultivo de la parte bajas del valle del Chillón sufrieron el mismo destino. En la visita hecha a Guancayo, Maca y Guaravni en 1571 se menciona la forma de cómo los naturales cumplían su tributo a los curacas principales del repartimiento de Huancayo Alto en tiempos del Inca, Espinoza (1963, p. 57) menciona:

[que en dicho tiempo hacían al principal cinco sementeras de maíz cada una de cuatro pocchas-le hacían chacra grande de ají y otras de fanega y media de frisoles y otra chacra de camote grande, y otra chacra de yuca y otra chacra grande de coca, donde cogía 20 cestos en cada mita y que asi mismo le sembraban y beneficiaban otra chacra de algodón y que le daban diez indios para amaqueros y otros cinco para pajes muchachotes y que mujeres tomaba todas las que el quería y que le hacían sus casas y asi mismo le daban dos indios viejos para porteros y que cada indio del repartimiento le daba cada año un carnero- no había mas que dos principales a los que se diese de servicio y tributo que eran el principal de Guaravni y el de Maca- que dichos servicios era perpetuo y si se moría mandaba otro en su lugar- y que dicho cacique daba de comer y vestir a dicho servicio].

Este testimonio permite comprender las relaciones entre gobernantes y gobernados a nivel local, lo que sugiere que estos señores debieron ocupar instalaciones diseñadas en relación de su estatus para cumplir con funciones administrativas impuestas por el estado, es decir residencias de élite con equipamientos arquitectónicos asociadas a funciones de vivienda palaciega como las identificadas en los sitios Cerro Respiro, Palacio Oquendo y Tambo Inca en el valle del Chillón.

Para el caso de valle bajo del Chillón, la información etnohistórica sobre la administración inca es general. Según la Visita de Juan Martines Rengifo de 1571, las pachacas de la guaranga Colli en tiempos de los incas declaradas por Hernando Nacara Cacique principal del pueblo de Collique comprendían diez pachacas ellas eran: Chuquiruro, Caxa Chumbi, Vilca Tanta, Vilca Chumbi, Chumbi Guarco, Chumbi Tanta, Carua Guanco, Carua Chumbi, Chinqui Yanga y Chuquitanta (Rostworowski, 2014, p. 42-43). En este documento colonial del siglo XVI, se hace mención también a la cantidad de fanegadas de tierras que cada pachaca poseía y como las tierras de cultivo habían pasado de propiedad de las pachacas a los herederos españoles hasta 1571.

Esta conformación de población en unidades administrativas de cinco y diez pachacas es interesante y concuerda con la forma de organización administrativa inca y habría sido establecida para tener un mejor control sobre los grupos de población asentados en el valle bajo del Chillón y la producción de bienes a través de un sistema de tributos de poblaciones especializadas que producían artefactos, alimentos, servicios y conformaba la fuerza laboral utilizada en las obras públicas como son la 
construcción de caminos, acequias y ampliación de los terrenos de cultivo y la producción agrícola en las tierras estatales.

En los contextos excavados del sitio Cerro Respiro se identificaron una variedad de productos cultivados, como maíz (Zea maíz) de distintas variedades en contextos de ofrendas y corontas de maíz al interior de uno de los depósitos. También restos de pallares (Phaseolus lunatus) y fréjoles (Phaseolus vulgaris) al interior de una vasija, semillas de calabaza (Cucurvita pepo), ají (Capsicun annum), camote (Hipomea batata), frutos secos, semillas de lucma (Pouteria lucuma), pacay (Inga feuillei), algodón (Gossypium herbaceum) sin procesar utilizado en los envoltorios de entierros y en la confección de textiles.

Si bien los productos agrícolas eran importantes para los incas como el ají, el maíz y el algodón, también lo eran otros productos como los recursos marinos para la dieta de los habitantes que vivieron en el sitio Cerro Respiro, en las investigaciones en el sitio se identificaron gran cantidad de huesos de pescado, restos de moluscos como Choros (Aulacomya atra), Mesodesma (Mesodesma donaciun), Concholeta (Concholepa concholepa), asociados a contextos domésticos, en los recintos excavados así como en contextos de las dos plazas. Entre los productos marinos destaca el Spondylus sp., ofrenda encontrada en la remodelación del patio central de la residencia de élite, conteniendo cuentas de espingo, estos productos no son locales, sino que su origen se ubica en zonas ecológicas distintas y alejadas a la costa central, como son la zona del ecuador y la selva amazónica. La presencia de estos productos en el sitio Cerro Respiro tiene un significado particular relacionado a un intercambio de productos y una dinámica económica con otras regiones.

Estos hallazgos confirman que el curaca que vivió en el sitio Cerro Respiro no sólo tuvo acceso privilegiado de la mano de obra y la producción agrícola, sino también a recursos del mar, del río, los humedales, recursos del valle medio y alto del Chillón a través de la red vial inca construida en ambas márgenes de la cuenca baja del valle.

\section{EL CAMINO INCA}

Se ha considerado que el camino inca o Qhapaq Ñan para los incas ha tenido diferentes significados, se menciona que fue un complejo sistema administrativo de transporte y de comunicación, un medio para describir las cuatro divisiones básicas del imperio, una red principal que comunicaba el Cusco y también como una red que describe la geografía estatal recordando los lugares y las gentes de acuerdo a su posición en el camino (Hyslop, 2017, p. 61). Pero también ha sido entendido como una red que facilitó el manejo de los diferentes pisos ecológicos en una suerte de articulación del medio físico con el aprovechamiento de sus recursos naturales y minerales, según las variaciones altitudinales y transversales del medio (Martines, 2010, p. 41-42). 
Teniendo en cuenta este último planteamiento, debemos considerar que la red vial posibilitó un control social y demográfico, facilitando el traslado de poblaciones de mitimaes de un lugar a otro del Imperio, por lo tanto, es también una herramienta de análisis para interpretar la administración y el manejo territorial. Es decir, el camino no solo integraba infraestructura, sino que conectaba a otros territorios, ya que junto al camino se ubicaban los asentamientos o tambos con equipamientos residenciales o alojamiento, plazas depósitos y otros, los cuales permitieron articular espacios administrativos, centros religiosos y santuarios.

Las investigaciones llevadas a cabo el año 2003, 2011 y 2016 en el valle bajo del Chillón permitieron identificar en la margen izquierda zona de Oquendo hasta Puente Inca pequeños segmentos del camino inca transversal que unía la costa- sierra los restos del camino se encuentran muy deteriorados producto del avance de las tierras de cultivo y por las construcciones de las urbanizaciones modernas que destruyeron y alteraron el aspecto físico del camino. Sin embargo, permiten reconstruir y explicar su importancia administrativa durante la época inca.

Las evidencias mejor conservadas se localizan cruzando el sitio Palacio Oquendo (figura 11). El trazo del camino cruza por el sitio arqueológico y se prolonga por la ladera baja del cerro en dirección norte en zona urbanizada. Este primer segmento, se encuentra construido por un muro lateral de tapial (camino corte talud) de regulares proporciones, tiene una calzada de $2.5 \mathrm{~m}$ de ancho y se prolonga unos $80 \mathrm{~m}$ de largo luego de cruzar el sector I del sitio Palacio Oquendo y parte de este segmento de camino fue cortado por la construcción de viviendas actuales que se ubican en esta zona.

Un segundo segmento se localiza en la parte lateral de una de las calles de la Urbanización Oquendo, presenta como característica principal un muro lateral de tapial de gran altura y calzada de $4 \mathrm{~m}$ de ancho, en la actualidad este muro del camino a quedado aislado dentro de la urbanización Oquendo. En la parte media junto a una pequeña colina natural se ubica un tercer segmento del camino, este tiene un muro de tapial hacia la pendiente del cerro y acondiciona un espacio de calzada transitable de $3 \mathrm{~m}$ de ancho (figura 11).

Hacia la altura del "Cementerio del Recuerdo" el camino tiene una difurcación, uno de los ramales se dirige a la Av. Gambeta, este segmento se proyecta unos 300 metros de largo tiene dos muros laterales con una calzada de $4 \mathrm{~m}$ de ancho y por su orientación debió prolongarse hasta el mar. El otro segmento del camino a partir de su bifurcación, se prolonga por el lado sureste del cementerio Parque del Recuerdo, tiene dos muros laterales de tapial de baja altura y una calzada de 3 a $4 \mathrm{~m}$ de ancho (figura 11), la evidencia registrada del camino se prolonga unos 295 metros de largo en dirección noreste y por su orientación debido comunicar con la zona de Márquez. 
Otro segmento fue identificado a la altura del sitio Arqueológico Capilla Márquez, bordeando el lado Noreste del Cerro las Ánimas, tiene un muro de contención hecho de tapial hacia la pendiente del cerro y acondiciona un espacio transitable de $3 \mathrm{~m}$ de ancho (figura 11).

En la zona de Chuquitanta es posible apreciar varios segmentos de muros de grandes dimensiones que comparten un mismo diseño constructivo. Esta sección del camino ha sido definida como "caminos epimurales" por Agurto Calvo (1983), quien considera que estos fueron construidos durante el Intermedio Temprano como parte de un conjunto de murallas que rodeaban asentamientos, terrenos de Cultivo y que incluida parte del litoral y zonas de asentamientos en el valle bajo del Chillón. Sin embargo, no es el único que registra este camino, de acuerdo a la propuesta de Jorge Silva (1996), este tipo de construcción correspondería a un camino epimural, que funcionó como camino para el tránsito de personas durante los Periodos Tardíos.

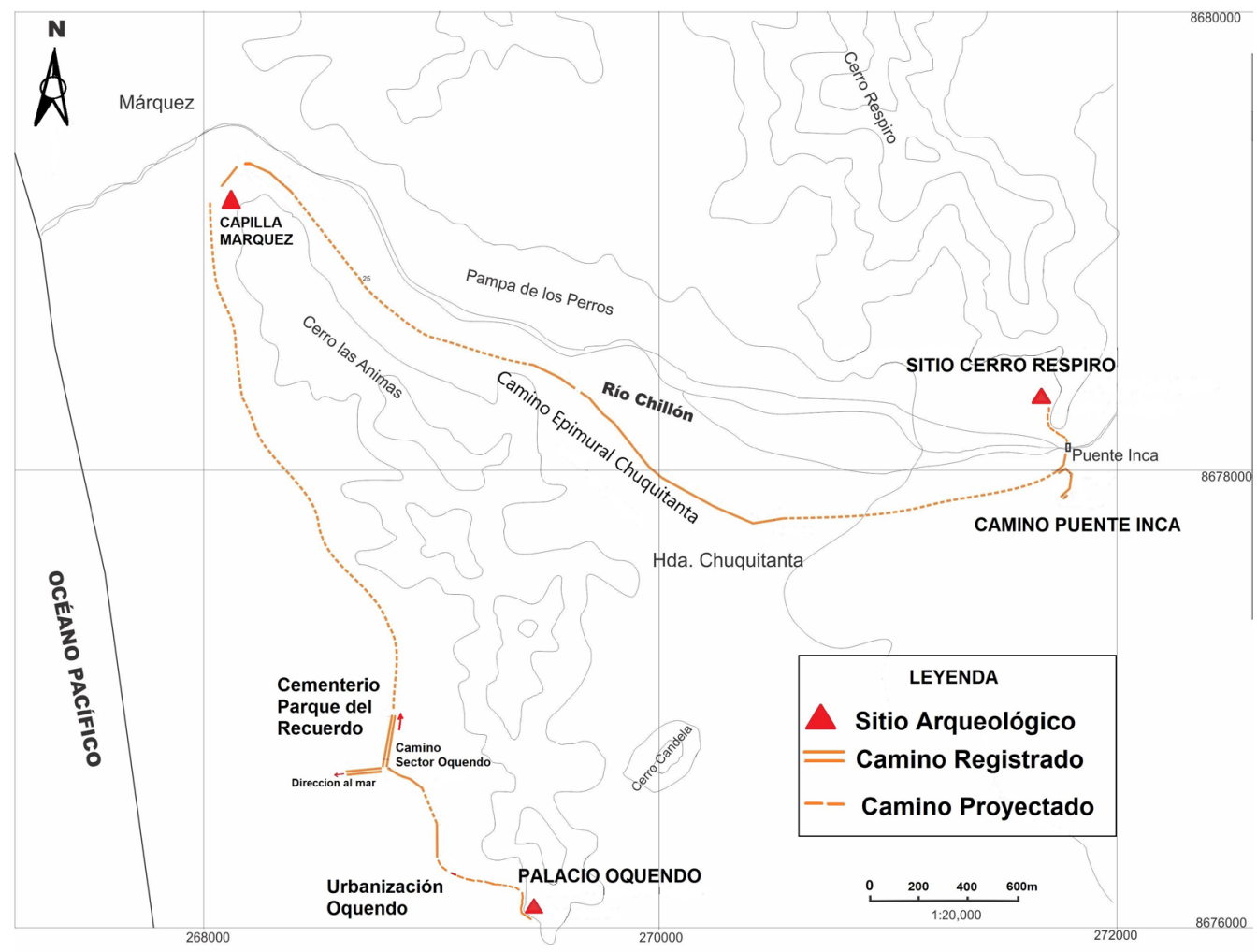

Figura 11. Segmentos del camino inca asociados a los sitios Palacio Oquendo, Cerro Santa Cruz, la Zona de Puente Inca y el sitio Cerro Respiro. 
En nuestros reconocimientos arqueológicos en la zona de Chuquitanta pudimos identificar la evidencia de 1,032 metros de este camino epimural de grandes dimensiones y que aún se pueden observar, tienen la forma troncocónica de base ancha y acabado superior de unos $2 \mathrm{~m}$ de ancho, su técnica constructiva es a través de diversos rellenos constructivos que evidencian la forma como fueron construidos, así como las modificaciones y alteraciones que en el camino se han realizado, en algunas partes de este camino es observable la reutilización de esta construcción a través de adobes que forman un muro lateral y rellenos constructivo para lograr una calzada transitable, la cual habría funcionado también durante la época inca (figura 11).

Antes de llegar a Puente Inca, en la margen izquierda se ubica otro segmento conservado con características arquitectónicas similares al camino de Oquendo, la evidencia más representativa del camino tiene dos muros laterales de tapia y otro segmento con un muro de contención hacia la pendiente, este último parciamente destruido por casas modernas del actual asentamiento que se ubica en el Cerro Santa Cruz. Este camino presenta una calzada es de $3 \mathrm{~m}$ de ancho y muros de más de $1 \mathrm{~m}$ de altura, es el más largo y se proyecta desde la zona de Puente Inca hacia la zona de los Olivos con dirección a los sitios de Aznapuquio y Huaca Naranjal (figura 11). En la zona baja del Cerro San Cruz, cerca de Puente Inca se ubica también un segmento corto de camino encerrado con muros de tapial que tiene una orientación sur, la evidencia registrada es de $50 \mathrm{~m}$ de largo y una calzada de $4 \mathrm{~m}$ de ancho y por su orientación debido comunicar con el camino epimural identificado en la zona de Chuquitanta. La presencia de este camino y el sitio arqueológico Cerro Santa Cruz ubicado cerca de la zona de Puente Inca, debido ser un lugar estratégico de control del puente relacionado al paso de una margen a otra y su articulación con el sitio Cerro Respiro (figura 1).

En cuanto a la evidencia del puente inca, en la actualidad ya no existe, solo quedan evidencias de los estribos que han sido reconstruidos con materiales modernos, según las investigaciones de Espinoza (1998) lo describe como una construcción de la época Republicana debido a las remodelaciones que tenía Sin embargo, las evidencias sugieren haber sido un puente de la época Inca, como es la proyección del camino que se dirige al puente, los sitios arqueológicos con ocupación Inca, Cerro Santa Cruz y Cerro Respiro, así como la ubicación de un paso estrecho de sólo $9 \mathrm{~m}$ de ancho, lugar estratégico de paso de una margen a otra. Estas características concuerdan con los puentes construidos por los Incas en lugares estratégicos donde se tuvieron en cuenta factores como el ancho del curso del río, tipos de material disponibles, profundidad y altura de sus márgenes (Hyslop 1992, p. 215).

Desde Puente Inca, hasta Tambo Inca, en la actualidad no existen evidencias del camino inca. Sin embargo, en la fotografía aérea de 1945 se observa que el camino se proyectaba por la margen derecha con dirección a Puente Piedra. En esta área 
amplia del valle bajo se ubican asentamientos humanos y urbanizaciones modernas que han destruido toda evidencias del camino, pero por su proyección debió interconectar al camino longitudinal de la costa a la altura de la zona de Changrilá cerca del cruce de la Panamericana norte y el río Chillón, para luego continuar por la antigua carretera hasta llegar al sitio de Tambo Inca y luego continuar hacia Ancón y el valle de Chancay.

Este camino debió facilitar la recolección de recursos naturales, alimentos, provisiones, tributos y traslado de la mano de obra, facilitar el tránsito del personal militar y los desplazamientos de los gobernantes Incas que inspeccionaban a sus súbditos en el valle bajo del Chillón. Es decir, fue un sistema transversal de transportes y comunicaciones que unía el valle bajo con el valle medio, con la cuenca alta del chillón y a su vez con la sierra central. En la zona del litoral debió interconectar la zona del bajo Rímac (Maranga y Surco) y el sitio de Pachacamac.

La ubicación del sitio arqueológico Cerro Respiro en relación al camino y el puente son evidencias de gran importancia que explican el control administrativo inca en el valle bajo y el curaca que ocupaba el sitio de Cerro Respiro debió administrar, supervisar y controlar no sólo el camino y el puente, sino también el paso de los productos de intercambio entre la costa y el valle medio del Chillón.

\section{CONCLUSIONES}

Los Incas en el valle bajo del Chillón no sólo se limitaron a ocupar sitios con arquitectura de tradición local anterior, sino que modificaron y alteraron el espacio al interior de los asentamientos, con la finalidad de satisfacer nuevas necesidades del estado.

La influencia inca en el sitio Cerro Respiro, se expresa en el trazo ortogonal, elementos arquitectónicos, hornacinas de forma rectangular y trapezoidal, muros escalonados, técnicas constructivas en muros de tapial y estilos de cerámica y textiles con diseños inca.

Las residencias de élite identificadas en los tres sitios, son en este sentido diferentes en cuanto al diseño arquitectónico, pero comparten elementos comunes con los grandes centros administrativos incas, como es el trazo ortogonal, muros protectores que definen un espacio restringido de vivienda tipo cancha, las que a su vez presentan ambientes asociados a un patio central o lateral con presencia de banquetas, que funciona como sala de recepción o audiencia, un elemento pasadizo que comunica a ambientes privados de vivienda, es parte de este tipo de edificio espacios destinados a actividades productivas como depósitos y secaderos, casi siempre se encuentran asociadas y articuladas a una plaza central a través de un pasadizo o vano de ingreso principal. 
El sitio Cerro Respiro durante la época inca, el espacio construido fue modificado considerablemente en su arquitectura, se construyeron nuevos ambientes, un área residencial de élite donde vivía el curaca o gobernante inca, lugar desde donde ejercía su poder político y tomaba decisiones sobre actividades administrativas, económicas y ceremoniales.

Las evidencias arquitectónicas, contextos arqueológicos y cultura material encontrados producto de la excavación, permite confirmar que el sitio arqueológico Cerro Respiro durante el Horizonte Tardío, funcionó como una residencia de élite o palacio, el cual no sólo cumplió funciones de alojamiento y vivienda de un personaje de alto estatus; sino que también, fue lugar donde se realizaban actividades administrativas de acopio, transformación y distribución de productos, así como el control del puente en relación al camino inca.

\section{REFERENCIAS BIBLIOGRÁFICAS}

Agurto, S. (1983). Los Murallones del Chillón. En: Revista Ingeniero Civil Arqueología, № 24: Mayo -Junio; Lima.

Aranguren, V. (2005). Reciprocidad e Intercambio: Colonias Chancay en el Valle Medio del Chillón; Tesis para optar el grado de Licenciado en Arqueología, Facultad de Humanidades de la Universidad Nacional Federico Villarreal. Lima.

Ayala, G. R (2008). El Sitio Arqueológico Cerro Respiro: Un caso de Residencia de Étile Inca en el Valle Bajo del Chillón. Tesis para optar el grado de Licenciado en Arqueología, Facultad de Humanidades de la Universidad Nacional Federico Villarreal. Lima.

Cobo, Fr. B. [1653]1983. Historia del Nuevo Mundo. Desde la formación del Lenguaje hasta nuestros días. Biblioteca de Autores Españoles. Madrid.

Cornejo, M. (2000). La Nación Ishma y la Provincia Inka de Pachacamac. Arqueología, 24, pp. 147 -173: Lima.

D’Altroy, T. (1992). Provincial Power in the Inca Empire. Smithsonian Institution. Washington.

D'Altroy, T. (2015). El poder provincial en el Imperio Inca. Banco Central de Reserva del Perú, Instituto de Estudios Peruanos. Lima.

Dillehay, T. D. (1976). Competition and Cooperation in a Multi-etanic Systen in the Central Andes. Tesis Doctoral, Department of Anthropology University of Texas; Estados Unidos.

Dillehay, T. D. (1997). Tawantinsuyu Integration of the Chillón Valley, Perú: A Case of Inca Geo-Political Mastery. En Journal of Field Archaeology. Volúmen 4, Number 4. Boston University. 
Dillehay, T. D. (2003). El Colonialismo Inka, el consumo de chicha y los festines desde una perspectiva de banquetes políticos. Boletín de Arqueología PUCP. № 7, pp. 151-187. Lima.

Eeckhout, P. y C. Farfán (1999). Informe Final Proyecto Ychsma Investigaciones Arqueológicas y Estudios de Restauraciones en el Sitio de Pachacamac. Excavaciones en la Pirámide 3. Bruselas y Lima; INC.

Eeckhout, P. (2003). Diseño Arquitectónico, Patrones de Ocupación y Formas de Poder en Pachacamac, Costa Central del Perú. En: Revista Española de Antropología Americana, №33, pp. 17-37.

Eeckhout, P. (2004). La Sombra de Ychsma- Ensayo Introductorio sobre la Arqueología de la Costa Central del Perú en los Períodos Tardíos. En: Boletín del Instituto Francés de Estudios Andinos, Tomo 33, № 3, pp. 403-423, Lima: IFEA.

Espinoza, M. R. (1998). Informe Final del Proyecto de Emergencia Investigación Arqueológica en Puente Inca Valle Bajo del Chillón. Lima: INC.

Espinoza, W. (1963). La Guaranga y la Reducción de Guancayo. Tres documentos inéditos de 1571, para la etnohistoria del Perú. Revista del Museo Nacional de Lima, tomo XXXII: 8 -20. Lima.

Gasparini, G y L. Margolies (1977). Arquitectura Inka. Centro de Investigaciones Históricas y Estéticas. Facultad de Arquitectura y Urbanismo. Universidad Central de Venezuela.

Hyslop, J. (1992). Qhapapñan el Sistema Vial Incaico. Instituto Andino de Estudios Arqueológicos. Lima.

Hyslop, J. (2017). Qhapaq Ñan el sistema vial incaico. Primera reimpresión de la segunda edición en Castellano. Ediciones Cope y Petroperú. Lima.

Ludeña, H. (1975). Secuencia Cronológica y Cultural del Valle del Chillón. Tesis Doctoral, Departamento Académico de Arqueología de la U.N.M.S.M. Lima.

Mackey, C. (2003). La Transformación Socioeconómica de Farfán Bajo el Gobierno Inka. En: Boletín de Arqueología PUCP № 7, pp. 321-353. Pontificia Universidad Católica del Perú. Lima.

Martínez, G. (2010). Qhapaq Ñan: El Camino Inca y las transformaciones territoriales en los Andes Peruanos. En: Arqueología y Sociedad, № 21. Pp. 37-62. Museo UNMSM.

Morris, C. (2016). El palacio, la plaza y la fiesta en el Imperio Inca. Colección de Estudios Andinos 13. Institute of Andean Research, New York y el Fondo de Editorial PUCP del Perú. Editores: John R. Topic, Joanne Pillsbury, Hearther Lechtman y Marco Curatola Petrocchi. Lima. 
Morris, C. y A. Covey. (2003). La Plaza Central de Huanuco Pampa: Espacio y Transformación. En: Boletín de Arqueología. PUCP № 7, pp. 133-149: Pontificia Universidad Católica del Perú. Lima.

Murúa, M. ([1590-1609]1962). Historia General del Perú, Origen y Descendencia de los Incas. Colección Joyas Bibliográficas, Biblioteca América Vetus, Madrid.

Rostworowski, M. (1972). Las Etnias del Valle del Chillón. En: Revista del Museo Nacional, Tomo. XXXVIII. Lima.

Rostworowski, M. (1992). Historia del Tawantinsuyu. IEP. Lima.

Rostworowski, M. (2014). Costa Peruana Prehispánica. Obras Completas. Volumen III. IEP. Lima.

Silva, J. (1991). Patrones de Poblamiento en el Valle del Chillón. Asociación Peruana para el Fomento de las Ciencias Sociales, Programa de Becas 1987 - 1988 Fonciencias. Lima.

Silva, J. (1996). Prehistorie Settlement Patterns In the Chillón River Valley, Perú Volumen I. Tesis Doctoral Department of Antropology. University of Michigan Horace H. Rackham School of Graduate Studies.

Thompson, D. (1970). La Ocupación Incaica en la Sierra Central del Perú (II) En: Arqueología: 16 - 20. Lima.

Uni y Ford. (1994). Inventario del Patrimonio Monumental Inmueble de Lima. Valles del Chillón, Rímac y Lurín, Lima: Facultad de Urbanismo Arquitectura y Artes (UNI) - Fundación FORD.

Villacorta, L. F. (2003). Palacios y Ushnus: Curacas del Rímac y Gobierno Inca en la Costa Central, Boletín de Arqueología 7, pp. 151-187. PUCP. Pontificia Universidad Católica del Perú. Lima.

Villacorta, L. F. (2004). Los Pobladores en la Costa Central durante los Períodos Tardíos: De Pachacamac al Inca. Boletín del Instituto Francés de Estudios Andinos, 33(2), 539 - 570; Lima.

Sack, R. (1983). Human Territoriality: A Theory. Annals of the Association of American Geographers, Vol. 73, No. 1. (Mar., 1983), pp. 55-74. 


\section{SOBRE EL AUTOR}

\section{Ronal Ayala Castillo}

Arqueólogo investigador de la Universidad Nacional Federico Villarreal, con estudios de maestría en Arqueología Andina en la Universidad Nacional Mayor de San Marcos, en la actualidad es docente en la Universidad Nacional Federico Villarreal, con interés de investigaciones sobre las construcciones públicas, la administración, el sistema vial y el manejo del territorio Inca. Ha realizado investigaciones en el sitio arqueológico Cerro Respiro. Es miembro asociado al Laboratorio de Arqueología de la Universidad Nacional Federico Villarreal. 